resonance imaging findings for surgical approach to reoperation. J AAPOS. 2006;10:340-344.

8. Coleman AL, Smyth RJ, Wilson MR, et al. Initial clinical experience with the Ahmed glaucoma valve implant in pediatric patients. Arch Ophthalmol. 1997;115:186-191.

9. Eid TE, Katz J, Spaeth GL. Long term effects of tube shunt procedures on management of refractory glaucoma. Ophthalmology. 1997;104:1011-1016.

10. Jonas JB, Spandau UH, Schlichtenbrede F. Intra-vitreal bevacizumab for filtering surgery. Ophthalmic Res. 2007;39:121-122.

11. Hurwitz H, Fehrenbacher L, Novotny W, et al. Bevacizumab plus irinotecan, fluorouracil and leukovorin for metastatic colorectal cancer. $N$ Engl J Med. 2004;350:2335-2342.

12. Rosenfeld PJ, Fung AE, Puliafto CA. Optical coherence tomography finding after an intravitreal injection of bevacizumab for macular edema of central vein occlusion. Ophthalmic Surg Lasers. 2005;36:336-339.

13. Davidoff FH, Mouser JG, Derick RJ. Rapid improvement of rubeosis iridis from a single bevacizumab (Avastin) injection. Retina. 2006;26:354-356.

14. Kahook MY, Schuman JS, Noecker RJ. Needle bleb revision of encapsulated filtering bleb with bevacizumab. Ophthalmic Surg Lasers Imaging. 2006;37:148-150.

15. Sothornwit N. Intravitreal bevacizumab for Ahmed glaucoma valve implantation in neovascular glaucoma: a case report. J Med Assoc Thai. 2008;91(suppl 1):S162-S165.

16. Lavin MJ, Franks WA, Wormald RPL. Clinical risk factors for failure in glaucoma tube surgery. Arch Ophthalmol. 1992; 110:480-485.

17. Spiegel D, Shrader PR, Wilson RP. Anterior chamber tube shunt to encircling band (Schoket's implant) in the treatment of refractory glaucoma. Ophthalmic Surg. 1992;23:804-807.

18. Valimaki J, Tuvlonen A, Airaksinen PJ. Capsule excision after failed Molteno surgery. Ophthalmic Surg Lasers. 1997;28: 382-386.

19. Beer PM, Wong SJ, Hammad AM, et al. Vitreous levels of unbound bevacizumab and unbound vascular endothelial growth factor in two patients. Retina. 2006;26:871-876.

20. Topouzis F, Coleman A, Alchoplin N. Follow up of the original cohort with the Ahmed glaucoma valve implant. $\mathrm{Am}$ J Ophthalmol. 1999;127:27-33.
21. Huang MC, Netland PA, Coleman AL. Intermediate term clinical experience with Ahmed Glaucoma valve implant. Am J Ophthalmol. 1999;127:27-33.

22. Perkins TW, Cardakli UF, Eisele JR, et al. Adjunctive mitomycin C in Molteno implants surgery. Ophthalmology. 1995;102:91-97.

23. Susanna JR, the Latin American Glaucoma Society SLAG Partial Tenon's capsule resection with adjunctive mitomycin C in Ahmed glaucoma valve implant surgery. Br J Ophthalmol. 2003;87:994-998.

24. Coleman AL, Hill R, Wilson MR, et al. Initial clinical experience with Ahmed glaucoma valve implant. $A m$ J Ophthalmol. 1995;120:23-31.

25. Ayyala RS, Zura Kowski D, Smith JA, et al. Clinical study of Ahmed glaucoma valve implantation in advanced glaucoma. Ophthalmology. 1998;105:1968-1976.

26. Costa VP, Azuara Blanco A, Netland PA, et al. Efficacy and safety of adjunctive mitomycin $\mathrm{C}$ during Ahmed glaucoma valve implantation. Ophthalmology. 2004;111:1071-1076.

27. Grewal DS, Jain R, Kumar $H$, et al. Evaluation of subconjunctival bevacizumab as an adjunct to trabeculectomy: a pilot study. Ophthalmology. 2008;115:2141.e2-2145.e2. [Epub August 9, 2008].

28. Shin JP, Lee JW, Sohn BJ, et al. In vivo corneal endothelial safety of intracameral bevacizumab and effect in neovascular glaucoma combined with Ahmed valve implantation. J Glaucoma. 2009;18:589-594.

29. Al-Mobarak F, Khan A. Two-year survival of Ahmed valve implantation in the first 2 years of life with and without intraoperative mitomycin-C. Ophthalmology. 2009;116: 1862-1865.

30. Alvarado JA, Hollander DA, Juster RP, et al. Ahmed valve implantation with adjunctive mitomycin $\mathrm{C}$ and 5-fluorouracil: long-term outcomes. Am J Ophthalmol. 2008;146:276-284.

31. Stein JD, McCoy AN, Asrani S, et al. Surgical management of hypotony owing to overfiltration in eyes receiving glaucoma drainage devices. J Glaucoma. 2009;18:638-641.

32. Takihara Y, Inatani M, Kawaji T, et al. Combined intravitreal bevacizumab and trabeculectomy with mitomycin $\mathrm{C}$ versus trabeculectomy with mitomycin $\mathrm{C}$ alone for neovascular glaucoma. J Glaucoma. 2010. [Epub ahead of print].

\title{
ERRATUM
}

\section{Correlations Between Corneal Biomechanical Properties Measured With the Ocular Response Analyzer and ICare Rebound Tonometry: Erratum}

In the article that appeared on page 442 of the volume 17 number 6 issue of the Journal of Glaucoma, approval for research projects was obtained from an internal review board instead of the Ethics Committee of the University of Minho as set forth in the Methods section.

Additionally, the following authors and degrees should have been listed as:

Jorge Manuel Martins Jorge, OD, PhD,* Jose M. González-Méijome, OD, PhD,* Antonio Queirós, OD,* Paulo Fernandes, OD,* Manuel A. Parafita, MD, $\mathrm{PhD}^{\dagger}$

\section{REFERENCE}

Jorge JMM, González-Méijome JM, Queirós A, et al. Correlations between corneal biomechanical properties measured with the ocular response analyzer and ICare rebound tonometry. J Glaucoma. 2008;17:442-448. 


\title{
Correlations Between Corneal Biomechanical Properties Measured With the Ocular Response Analyzer and ICare Rebound Tonometry
}

\author{
Jorge Manuel Martins Jorge, PhD,* Jose M. González-Méijome, PhD,* Antonio Queirós, MD,* \\ Paulo Fernandes, MD,* and Manuel A. Parafita, PhD $\dagger$
}

\begin{abstract}
Purpose: To investigate the biomechanical properties of the normal cornea, and correlate them with central and peripheral corneal thickness and age.
\end{abstract}

Methods: Seventy-six right eyes of volunteers were measured with Ocular Response Analyzer (ORA), ICare rebound tonometry and an ultrasound pachymeter at corneal center and at $4 \mathrm{~mm}$ from corneal center in the nasal and temporal directions.

Results: ICare readings were significantly correlated with central and peripheral corneal thickness and corneal biomechanical properties. Corneal resistance factor was the biomechanical parameter with the higher correlation with ICare intraocular pressure (IOP) values. ICare tonometry at center and Goldmann equivalent IOP obtained with ORA were significantly higher for thicker than thinner corneas $(P<0.05)$. IOP compensated for corneal properties with the ORA was lower than the remaining IOP values measured in the study. Higher correlation was found between Goldmann equivalent IOP with ORA and ICare IOP values.

Conclusions: IOP values obtained with the rebound tonometer are higher in thicker corneas and are positively correlated with biomechanical corneal parameters, namely corneal resistance factor. Although corneal thickness plays a significant role in rebound tonometry, elastic and viscous properties of the cornea seem to play a significant role in the interaction of the tonometer probe with the ocular surface. However, the mechanism behind this process is presently unknown.

Key Words: corneal biomechanics, Ocular Response Analyzer, corneal thickness, rebound tonometry, intraocular pressure

( J Glaucoma 2008;17:442-448)

Received for publication February 2, 2007; accepted October 20, 2007. From the *Department of Physics (Optometry), School of Sciences, University of Minho, Braga, Portugal; and $†$ Department of Surgery (Ophthalmology), School of Optics and Optometry, University of Santiago de Compostela, Santiago de Compostela, Spain.

Disclosure: None of the authors has a commercial or financial interest in the instruments or materials used in the study.

Reprints: Jorge Manuel Martins Jorge, PhD, Department of Physics (Optometry), Campus de Gualtar, University of Minho, 4710-057 Braga, Portugal (e-mail: jorge@fisica.uminho.pt).

Copyright (C) 2008 by Lippincott Williams \& Wilkins ntraocular pressure (IOP) measurements with conventional devices have demonstrated to be sensitive to corneal thickness variations. ${ }^{1-3}$ In fact, patients with reduced corneal thickness are at a higher risk of suffering from normal or low tension glaucoma and glaucoma damage. ${ }^{4,5}$ This is of major relevance in eyes that have undergone refractive surgery. ${ }^{6}$ However, the biomechanical properties of the cornea can also vary significantly without changes in corneal thickness and this could also affect IOP reliability. In fact, all tonometers that measure through the application of a stress to the corneal tissue are subject to the effects of corneal resistance. This corneal resistance is actually an "effective property" type of parameter. That is, rather than being a specific, intrinsic mechanical parameter like Young's modulus, corneal resistance is a composite parameter that incorporates the material and geometric properties of the tissue, including the time and spatial dependence of the underlying corneal material properties.

Different instruments have been recently developed for the direct measure of the biomechanical properties of the cornea. A review of those techniques can be found in the literature. ${ }^{8}$ However, most recent approaches are based on the noninvasive (air-puff) or invasive (direct contact of a tip) application of a controlled mechanical stress. ${ }^{8,9}$ The Reichert ORA (Reichert Inc, Depew, NY) determines corneal biomechanical properties using an applied force-displacement relationship by an air-puff similar to that used in traditional noncontact tonometry. ${ }^{9}$ Parameters used to characterize the biomechanical properties of the cornea include corneal hysteresis $(\mathrm{CH})$ and corneal resistance factor $(\mathrm{CRF})$. $\mathrm{CH}$ depends on the energy absorbed by the cornea when its tissue is submitted to stress and relaxation, thus inducing a delay in the corneal response to those forces. ${ }^{9}$ However, it is necessary to consider that $\mathrm{CH}$ and $\mathrm{CRF}$ are composite measures, which characterize the structural response of the eye to the measurement device rather than intrinsic material properties of the cornea, such as Young's modulus. This means that what we call "biomechanical properties" do not represent a specific property of the corneal tissue, but the response of the entire corneal structure to the ORA's measuring principle. As a result, these properties are only measurable by the ORA - a different device could potentially provide some other 
measure of biomechanical properties. In addition, ORA provides 2 measurements of IOP, one that is equivalent to Goldmann applanation tonometry (GAT) (IOPg) and the other compensated for the corneal biomechanical properties of the cornea (IOPc).

Considering the new methods used for IOP measurement as rebound tonometry, new concerns arise because of the biomechanical properties of the cornea and the potential influence of such properties on rebound tonometry. ORA uses the delay of corneal response after the applanation process to estimate the amount of energy absorbed, and derivate viscous and elastic properties of the cornea. In rebound tonometry, the absorbed energy could also delay the corneal response when the impact is applied to the cornea to measure IOP. According to this assumption, we could hypothesize that rebound of a small tip, as that used by the ICare tonometer (Tiolat Oy, Helsinki, Finland), could be affected by the biomechanical properties of the cornea. Despite this, no significant changes in IOP were found at thicker corneal periphery in normal corneas in the previous experiments carried out at our group. ${ }^{10,11} \mathrm{~A}$ complete description of this instrument and its functioning can be found in the literature. ${ }^{12-18}$

In the present study, the Reichert's ORA was used to evaluate the correlations between corneal biomechanical properties with the IOP obtained with a rebound tonometer.

\section{MATERIALS AND METHODS}

Seventy-six right eyes of volunteers were evaluated with ORA and ICare rebound tonometer. ORA measurements were taken centrally as recommended by the manufacturer. Mean age was $33.0 \pm 11.8$ within a range from 19 to 60 years of age.

Inclusion criteria required that the subjects presented no corneal pathology or corneal scarring had no previous ocular surgery nor were taking any ocular medications. Despite some patients presented with high IOP values, none of them were taking any medication as this was the first time they had been made aware of this situation. After the purpose and procedures of the study were fully explained, each patient gave the consent to participate in the study. Study protocol followed the tenets of the Declaration of Helsinki and was reviewed by the Ethics Committee of the University of Minho.

ICare rebound tonometry was measured centrally $\left(\mathrm{IC}_{\mathrm{c}}\right)$ and at 2 peripheral locations along the horizontal meridian in the nasal $\left(\mathrm{IC}_{\mathrm{n}}\right)$ and temporal regions $\left(\mathrm{IC}_{\mathrm{t}}\right)$. Peripheral measurements were taken at approximately $2 \mathrm{~mm}$ from limbus. In addition, ultrasound corneal thickness measurements at approximately the same locations $\left(\mathrm{CT}_{\mathrm{c}}, \mathrm{CT}_{\mathrm{n}}\right.$, and $\left.\mathrm{CT}_{\mathrm{t}}\right)$ were obtained with a Tomey SP-100 Handy (Tomey, Nagoya, Japan), whose accuracy and repeatability had been recently assessed. ${ }^{19}$ Pachometry examinations were carried out after the application of topical tetracaine hydrochloride $(0.5 \%)$. After sterilization using hydrogen peroxide $(3 \%)$ and rinsing with saline, an ultrasound probe was applied as perpendicular as possible to the cornea. Triplicate measurements were taken consecutively. To ensure precision in repositioning ultrasound probe at peripheral locations, all measurements were taken by the same investigator with the aid of a fixation panel. The patient was seated with the head placed on a chinrest $0.8 \mathrm{~m}$ away from the fixation panel. While their probe remains in the same position as it was when measuring central thickness, the eye turns to fixate each of the corresponding lightemitting diode's on the panel so that the probe can be placed at discrete locations over the cornea. Simple equations define the trigonometric relationship between the position of the fixation light-emitting diode's on the panel and the corneal location to be measured. This method has been probed to offer good reproducibility in peripheral computed tomography (CT) measurements. ${ }^{20-23}$ Tonometry measurements with ORA and ICare in a randomized order were always taken before ultrasound pachometry. All instruments were calibrated before commencement of the study.

Data were analyzed using the statistical package SPSS version 14.0 (SPSS Inc, Chicago, IL). Normality of data was evaluated with Kolmogorov-Smirnov test. Differences between IOP values with ORA and ICare were evaluated using 1-way analysis of variance (ANOVA) with Bonferroni post hoc correction. Parametric correlations were used for normally distributed variables, whereas nonparametric (Kruskall-Wallis) tests were used when normal distribution could not be assumed. Correlation coefficients were used to quantify the correlations among biomechanical, tonometric, and pachometric measurements, respectively. The sample was divided into 2 groups according to median central corneal thickness value. Values of IOP and biomechanical properties were compared for thinner and thicker corneas using 1-way ANOVA. The level of significance was established at $\alpha=0.05$.

\section{RESULTS}

Descriptive statistics for the parameters measured in the study are presented in Table 1. Corneal thickness measurements were significantly different between the 3 corneal positions measured with peripheral nasal and temporal readings being thicker than central ones (ANOVA; $P<0.001$ ); furthermore, nasal thickness was also significantly higher than temporal thickness taken at the same distance from limbus (ANOVA; $P<0.001$ ). The 3 ICare readings were also significantly different between the center and the periphery (Kruskall-Wallis, $P=0.018$ ) with temporal IOP being significantly higher than nasal and central readings. In addition, IOP readings were highly correlated among each other (Pearson coefficient $>0.800 ; P<0.001)$.

Patient's age was positively correlated with IOPg (0.406, $P<0.001)$, IOPc $(0.392, \quad P<0.001)$, corneal resistance factor (CRF) $(0.277, P<0.015)$, and $\mathrm{IC}_{\mathrm{c}}$ $(0.246, P<0.033)$, but not with corneal thickness in any of the 3 locations measured $(P>0.1)$. 
TABLE 1. Descriptive Statistics for the Parameters Measured With ORA, ICare, and US Pachometry

\begin{tabular}{|c|c|c|c|c|c|c|}
\hline Instrument & Measure & ID & Mean & $\begin{array}{l}\text { Standard } \\
\text { Deviation }\end{array}$ & Minimum & Maximum \\
\hline \multicolumn{7}{|l|}{ ORA $(\mathrm{mm} \mathrm{Hg})$} \\
\hline IOP & IOPg & $\mathrm{IOP}_{\mathrm{g}}$ & 15.47 & 3.43 & 8.40 & 23.20 \\
\hline \multirow[t]{2}{*}{$\mathrm{BP}$} & CRF & CRF & 10.68 & 1.97 & 5.50 & 16.60 \\
\hline & $\mathrm{CH}$ & $\mathrm{CH}$ & 10.73 & 1.69 & 6.90 & 15.50 \\
\hline \multirow[t]{2}{*}{ ICare rebound tonometer $(\mathrm{mm} \mathrm{Hg})$} & Center & $\mathrm{IC}_{\mathrm{c}}$ & 17.17 & 4.04 & 8.00 & 27.00 \\
\hline & Nasal & $\mathrm{IC}_{\mathrm{n}}$ & 16.83 & 3.89 & 10.00 & 29.00 \\
\hline \multirow{2}{*}{ Ultrasound pachometer $(\mu \mathrm{m})$} & Nasal & $\mathrm{CT}_{\mathrm{n}}$ & 609.24 & 38.69 & 537.00 & 698.33 \\
\hline & Temporal & $\mathrm{CT}_{\mathrm{t}}$ & 574.80 & 38.43 & 484.00 & 662.33 \\
\hline
\end{tabular}

Circles represent outliers

$\mathrm{n}=76$.

$\mathrm{BP}$ indicates biomechanical properties.

Figure 1 displays a graphical representation of the IOP values obtained with the ORA and ICare. Temporal IOP obtained with ICare was significantly higher than IOPg and IOPc obtained with ORA (ANOVA, $P=0.001$ and $P<0.001$, respectively). Marginally significant differences were also detected between ICare IOP readings obtained in the nasal and temporal locations (ANOVA, $P=0.028$ ). From this graphic representation, we can conclude that ICare displays higher and more variable results than ORA. IOPg and IOPc seem to be more reliable with the lower interquartile ranges and the least differences between maximum and minimum values and no outliers.

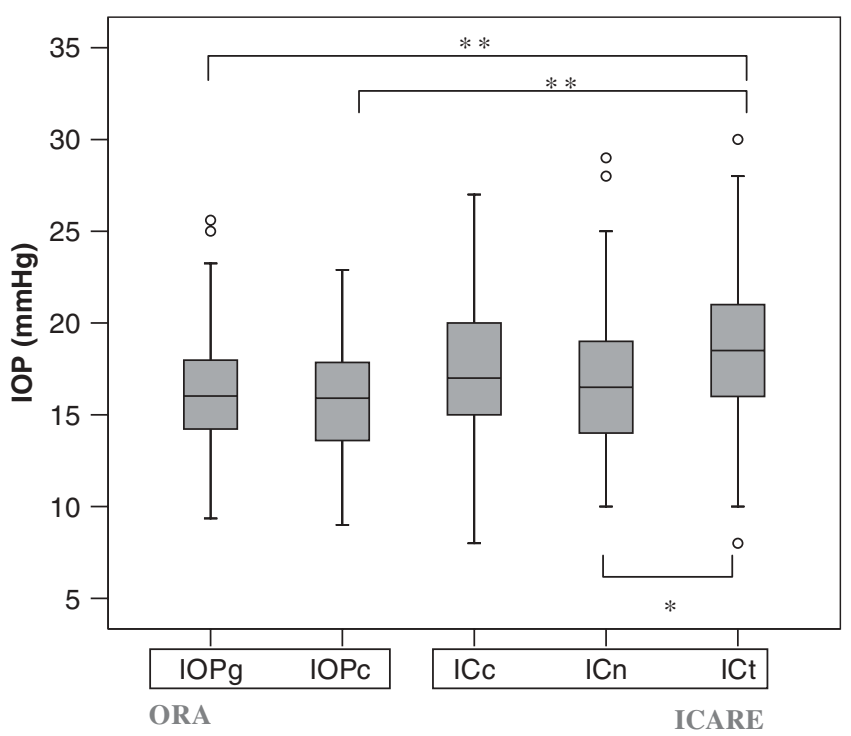

FIGURE 1. Boxplots of IOP values and statistical comparison among each other. ANOVA, post hoc Bonferroni corrected $P$ values. *Mean values are statistically significant (ANOVA, $P<0.05$ ). ${ }^{* *}$ Mean values are statistically significant (ANOVA, $P<0.001)$.
Regarding the agreement between IOP values obtained with ORA and ICare, stronger correlations were found between IOPg than IOPc, although all correlations were high and statistically significant $(P<0.001)$. Regression analysis presented in Figure 2 depicts the same results.

Table 2 displays the significant correlations among the biomechanical parameters $(\mathrm{CRF}$ and $\mathrm{CH})$ and the remaining parameters under investigation. Stronger correlations were found for $\mathrm{CRF}$ than for $\mathrm{CH}$ with the IOP values obtained with the ICare rebound tonometer. These relationships are illustrated in Figure 3.

Correlations of the ICare IOP readings with corneal thickness are presented in Table 3 with both parameters being significantly correlated, particularly with corneal thickness at center and nasal locations. Figure 4 shows the relationship between ICare readings and corneal thickness. Despite the significance of correlation and regression analyses, this relationship is weaker than that observed with CRF presented in Table 2 and Figure 3.

Median value for central corneal thickness was $540 \mu \mathrm{m}$. The sample was divided into 2 groups and the different values of IOP were averaged to evaluate if any difference was present among thinner $(\leq 540 \mu \mathrm{m})$ and thicker corneas $(>540 \mu \mathrm{m})$. Values as presented in Figure 5. According to this division, IOPg, CRF, $\mathrm{CH}, \mathrm{IC}_{\mathrm{c}}, \mathrm{IC}_{\mathrm{n}}$, and $\mathrm{IC}_{\mathrm{t}}$ were significantly higher for thicker than thinner corneas (ANOVA, $P<0.05$ ). An additional statistical analysis was repeated by splitting the eyes into groups considering grouping the eyes into 4 groups of equal number by corneal thickness and assigning the lower quartile to the thin cornea group, and the highest quartile to the thick cornea group not to bias the results by inclusion of the central group of patients that have neither thin nor thick corneas. According to this analysis, thin corneas were considered as CT \& $<510 \mu \mathrm{m}$ and thick corneas as having CT $>561 \mu \mathrm{m}$ but the results were the same as for the previous cut-off criteria of $540 \mu \mathrm{m}$.

Conversely, IOPc did not display such a dependency on central corneal thickness. This result is expected 

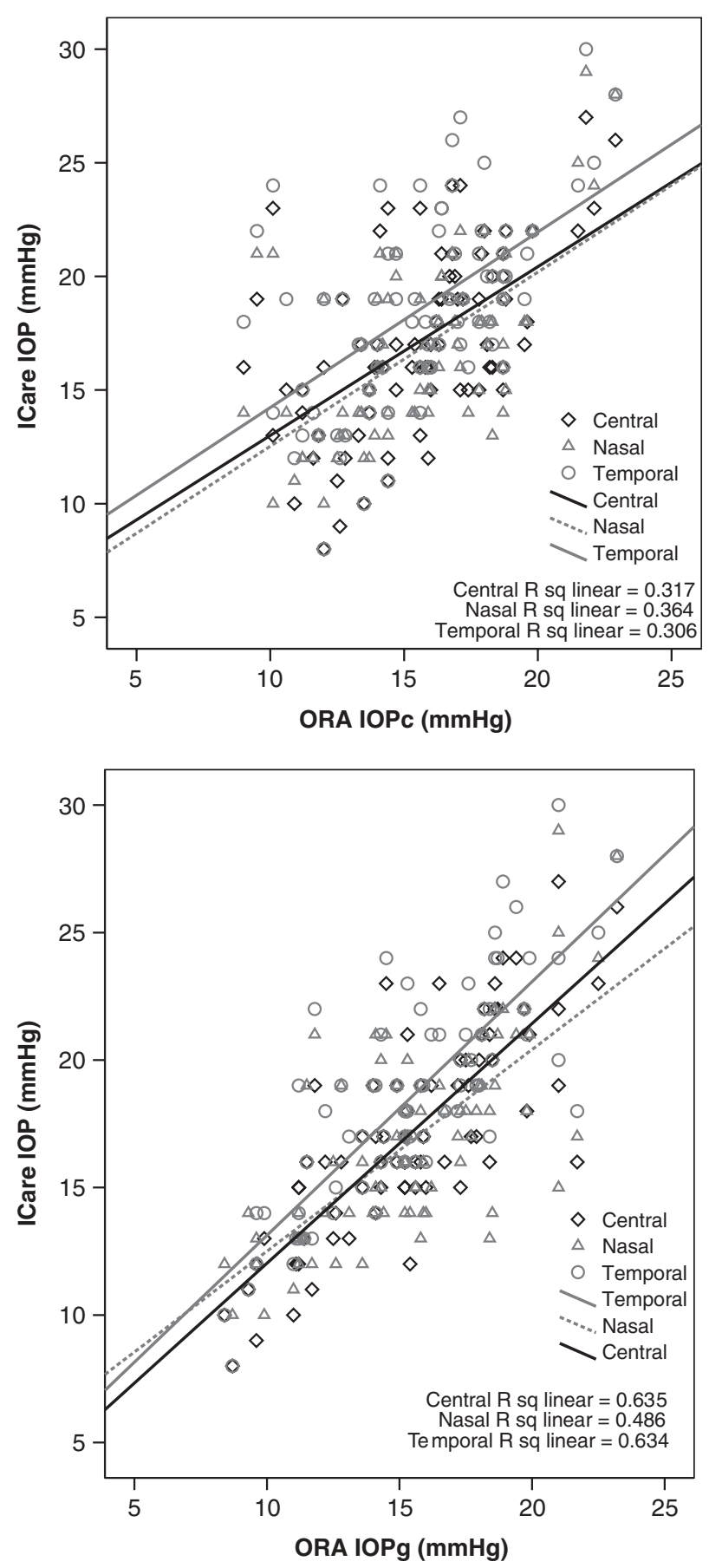

FIGURE 2. Relationship between ICare and ORA IOP.

because IOPc is designed to compensate for the overall biomechanical response of the cornea, in which central corneal thickness plays a role.

\section{DISCUSSION}

Regression analysis showed that ICare measures have higher correlation with biomechanical properties of the cornea as represented by the CRF (Table 2) than
TABLE 2. Significant Correlations of Biomechanical Parameters CRF and $\mathrm{CH}$ Obtained With the ORA With the Remaining Parameters Measured in the Study

\begin{tabular}{|c|c|c|}
\hline & $\begin{array}{l}\text { Correlation } \\
\text { Coefficient } \\
\end{array}$ & $\begin{array}{c}\text { Statistical Significance } \\
\text { (2-tailed) }\end{array}$ \\
\hline \multicolumn{3}{|l|}{ CRF vs. } \\
\hline $\mathrm{CH}$ & $0.779^{*}$ & $P<0.001$ \\
\hline $\mathrm{IC}_{\mathrm{c}}$ & $0.699 *$ & $P<0.001$ \\
\hline $\mathrm{IC}_{\mathrm{n}}$ & $0.489^{*}$ & $P<0.001$ \\
\hline $\mathrm{IC}_{\mathrm{t}}$ & $0.702 *$ & $P<0.001$ \\
\hline $\mathrm{CT}_{\mathrm{c}}$ & $0.696^{*}$ & $P<0.001$ \\
\hline $\mathrm{CT}_{\mathrm{n}}$ & $0.627^{*}$ & $P<0.001$ \\
\hline $\mathrm{CT}_{\mathrm{t}}$ & $0.629^{*}$ & $P<0.001$ \\
\hline \multicolumn{3}{|l|}{$\mathrm{CH}$ vs. } \\
\hline $\mathrm{IC}_{\mathrm{c}}$ & $0.287^{*}$ & $P=0.012$ \\
\hline $\mathrm{IC}_{\mathrm{n}}$ & $0.078^{*}$ & NS \\
\hline $\mathrm{IC}_{\mathrm{t}}$ & $0.358 \dagger$ & $P=0.002$ \\
\hline $\mathrm{CT}_{\mathrm{c}}$ & $0.609 \dagger$ & $P<0.001$ \\
\hline $\mathrm{CT}_{\mathrm{n}}$ & $0.519 \dagger$ & $P<0.001$ \\
\hline $\mathrm{CT}_{\mathrm{t}}$ & $0.567 \dagger$ & $P<0.001$ \\
\hline
\end{tabular}

corneal thickness itself (Table 3). Previous studies have also reported a trend for ICare IOP overestimation in thicker corneas. ${ }^{18}$ However, to the best of our knowledge, this is the first study analyzing the central and peripheral correlations between ICare IOP and corneal thickness with the corneal biomechanical properties.

$\mathrm{CH}$ and corneal thickness demonstrated a much higher correlation than in previous studies. ${ }^{5}$ However, $\mathrm{CH}$ did not demonstrate a correlation with ICare readings as high as did CRF, but a significant correlation was still found between $\mathrm{CH}$ and ICare IOP measured in the temporal cornea. $\mathrm{CH}$ is a function of the energy absorbed by the corneal tissue during applanation and relaxation. Energy absorption could also affect the measurement with the ICare tonometer as this measurement correlates with the inverse of the probe's deceleration speed after the impact with the cornea. This could explain the relationship obtained between ICare IOP and $\mathrm{CRF}$, and at a lower level with $\mathrm{CH}$. This relationship was not present with Goldmann tonometry where a contact method, not impact as in rebound tonometry, is used to obtain the measurement. Theoretically, a cornea with higher values of $\mathrm{CH}$ would display a longer delay in response to stress and relaxation forces, which indirectly means that it absorbs more energy when the air-puff is directed towards its tissue. For an impact based method of IOP measurement, this would mean that the higher the $\mathrm{CH}$, the higher the ICare reading would be assuming that a higher amount of energy absorbed by the cornea would induce a more rapid deceleration in the tip displacement. This is in fact the trend we have found in the present study. On the other hand, less attention has been paid to the ORA's CRF.

According to the ORA's inventor, $\mathrm{CH}$ is more directly linked to the elastic properties of the cornea whereas the CRF is a measurement of the cumulative 

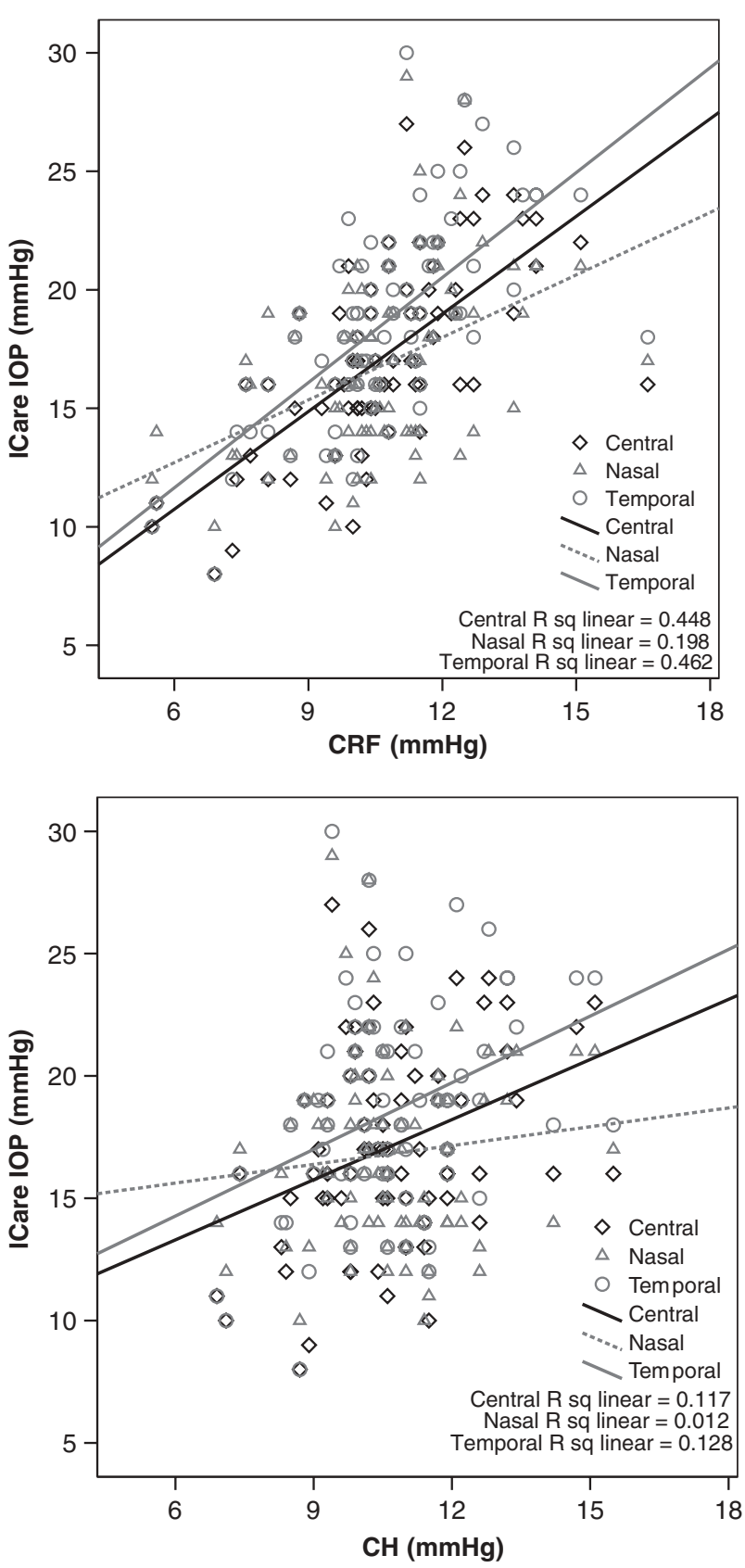

FIGURE 3. Regression analysis of IOP obtained with ICare at different corneal locations and CRF measured with ORA.

effects of viscous and elastic resistance encountered by the air-puff during the aplanation of the corneal surface. ${ }^{7,9}$ Regarding to the correlation with IOP, CRF is positively related with IOP, increasing at significantly elevated pressures. Conversely, no change or a slight decrease in $\mathrm{CH}$ has been documented for higher IOP values. The highly significant positive correlation between ICare readings and $\mathrm{CRF}$ could indicate that ICare readings are affected by other corneal properties and not only by corneal viscous properties. However, the isolated impact of corneal thickness, elastic and viscous tissue properties
TABLE 3. Significant Correlations of IOP Values Obtained With the ICare Rebound Tonometer With the Remaining Parameters Measured in the Study

\begin{tabular}{rcc}
\hline & Correlation Coefficient & \multicolumn{2}{c}{ Statistical Significance (2-tailed) } \\
\hline $\mathrm{IC}_{\mathrm{c}}$ vs. & & \\
$\mathrm{CT}$ & $0.466^{*}$ & $\mathrm{P}<0.001$ \\
$\mathrm{CT}_{\mathrm{n}}$ & $0.417^{*}$ & $\mathrm{P}<0.001$ \\
$\mathrm{CT}_{\mathrm{t}}$ & $0.419^{*}$ & $\mathrm{P}<0.001$ \\
$\mathrm{IC}_{\mathrm{n}} \mathrm{vs}$. & & \\
$\mathrm{CT}$ & $0.167^{*}$ & $\mathrm{NS}$ \\
$\mathrm{CT}_{\mathrm{n}}$ & $0.245^{*}$ & $\mathrm{P}=0.034$ \\
$\mathrm{CT}_{\mathrm{t}}$ & $0.154^{*}$ & $\mathrm{NS}$ \\
$\mathrm{ICt} \mathrm{vs.}_{\mathrm{CT} .}$ & $\mathrm{P}<0.001$ \\
$\mathrm{CT}_{\mathrm{c}}$ & $0.476 \dagger$ & $\mathrm{P}<0.001$ \\
$\mathrm{CT}_{\mathrm{n}}$ & $0.459 \dagger$ & $\mathrm{P}<0.001$ \\
$\mathrm{CT}_{\mathrm{t}}$ & $0.419 \dagger$ & \\
\hline
\end{tabular}

Correlations among ICare readings are not displayed but they are statistically significant. Correlations between ICare measurements and biomechanical properties of the cornea have been presented in Table 2 .

$\mathrm{n}=76$.

*Spearman coefficient (nonparametric correlation).

$\dagger$ Pearson coefficient (parametric correlation).

in IOP values obtained by rebound tonometry and other methods is presently unknown.

The stronger correlation found in the present study between ICare IOP values and Goldmann (GAT) equivalent IOP value (IOPg) agrees with previous studies on the relationships between conventional and portable GAT with ICare. ${ }^{16,17}$ Conversely, the lower correlation found when ICare IOP values were correlated to IOP compensated for the corneal properties (IOPc) suggests that ICare readings are affected by corneal properties and not only by the actual IOP of the eye. The higher correlation of IOP with biomechanical properties than corneal thickness agrees with the theories postulated by previous investigators, ${ }^{24}$ and suggests that corneal response to stress and relaxation forces during tonometric measurements is much more complex than an anatomical question related to corneal thickness changes.., 25

In previous experiments conducted at our group, we were unable to find a consistent relationship between IOP values measured with the rebound tonometer and increased peripheral corneal thickness in normal corneas ${ }^{10,11}$; in fact $80 \%$ of the eyes displayed peripheral values within $\pm 1 \mathrm{~mm} \mathrm{Hg}$ of the central reading. Moreover, in many situations, we could even obtain higher values of IOP within the thinner central cornea than at thicker corneal periphery. Similar results were obtained in the present sample. In another study, comprising a larger number of patients within a wide range of ages, we had observed that ICare readings decreased with age, and this decrease was significant for peripheral readings. ${ }^{10}$ In this study, we were not able to reproduce the results obtained previously. However, the spectrum of age is significantly more limited in this occasion. Considering all data presently available, we can conclude that the ICare rebound tonometer is not sensitive to increased peripheral corneal thickness as previously measured in other 

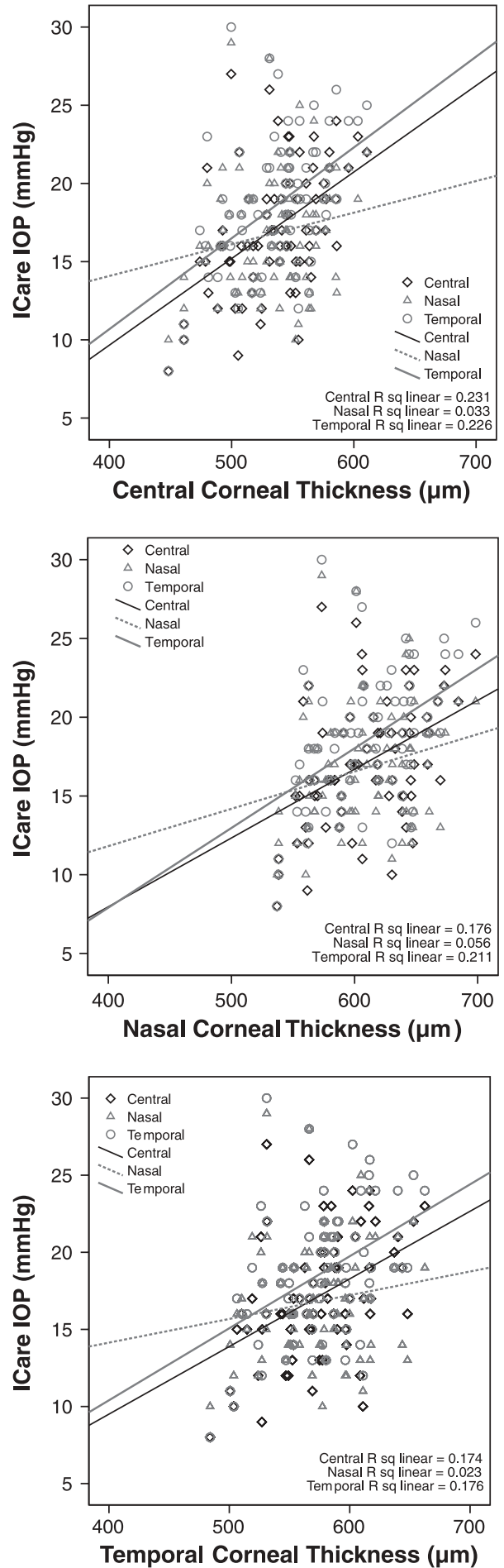

FIGURE 4. Regression analysis of IOP obtained with ICare at different corneal locations against corneal thickness.

studies $^{10,11}$; but at the same time thicker corneas have, on average, higher IOP values with the same instrument. We could hypothesize that for a certain cornea, with its particular physiologic, histologic, and microstructural

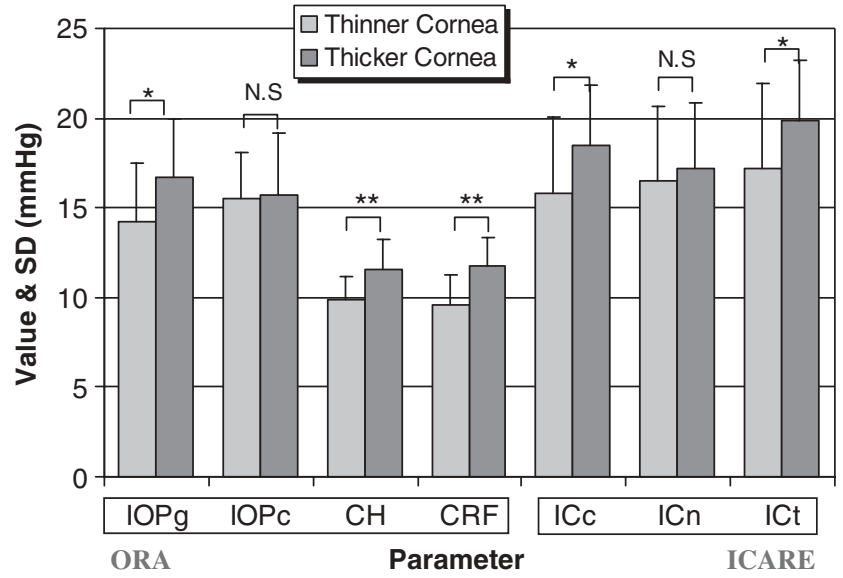

FIGURE 5. Comparison of tonometry and biomechanical properties for thinner $(\leq 540 \mu \mathrm{m})$ and thicker corneas $(>540 \mu \mathrm{m})$. NS indicates nonsignificant; ${ }^{*} P<0.05 ;{ }^{* *} P<0.001$.

characteristics, a significant increase in thickness in the periphery does not cause a significantly different response to the impact of the ICare tonometer. We believe that "individual physiologic variations in corneal material properties (the elastic and viscoelastic responses) may be a more important determinant of corneal structural response than corneal thickness." This is consistent with the arising common thought that complex relationships between corneal thickness and biomechanical properties of the cornea could affect the IOP readings.

To elucidate the potential effect of corneal properties other than corneal thickness in rebound tonometry, further investigations should be carried out involving patients affected of different corneal conditions as keratoconus, corneal thinning because of refractive surgery, or chronic corneal edema.

\section{ACKNOWLEDGMENTS}

The authors thank Optometron Instrumentos Ópticos e Electrónicos Lda for the loan of the Ocular Response Analyzer, IZASA Portugal for the loan of the SP-100 Handy Pachometer, and I30 Lda for the loan of the ICare rebound tonometer.

\section{REFERENCES}

1. Browning AC, Bhan A, Rotchford AP, et al. The effect of corneal thickness on intraocular pressure measurement in patients with corneal pathology. Br J Ophthalmol. 2004;88:1395-1399.

2. Doughty MJ, Zaman ML. Human corneal thickness and its impact on intraocular pressure measures: a review and meta-analysis approach. Surv Ophthalmol. 2000;44:367-408.

3. Ehlers N, Hjortdal J. Corneal thickness: measurement and implications. Exp Eye Res. 2004;78:543-548.

4. Jordan JF, Joergens S, Dinslage S, et al. Central and paracentral corneal pachymetry in patients with normal tension glaucoma and ocular hypertension. Graefes Arch Clin Exp Ophthalmol. 2006;244: 177-182.

5. Congdon NG, Broman AT, Bandeen-Roche K, et al. Central corneal thickness and corneal hysteresis associated with glaucoma damage. Am J Ophthalmol. 2006;141:868-875. 
6. Montes-Mico R, Charman WN. Intraocular pressure after excimer laser myopic refractive surgery. Ophthalmic Physiol Opt. 2001;21: 228-235.

7. Luce D, Taylor D. Reichert Ocular Response Analyzer measures corneal biomechanical properties and IOP. Ocular Response Analyzer White Paper. Available at: http://www.ocularresponseanalyzer.com/downloads.html 2005; Accessed November 2006.

8. Grabner G, Eilmsteiner R, Steindl C, et al. Dynamic corneal imaging. J Cataract Refract Surg. 2005;31:163-174.

9. Luce DA. Determining in vivo biomechanical properties of the cornea with an ocular response analyzer. J Cataract Refract Surg. 2005;31:156-162.

10. Gonzalez-Meijome JM, Jorge J, Queiros A, et al. Age differences in central and peripheral intraocular pressure using a rebound tonometer. Br J Ophthalmol. 2006;90:1495-1500.

11. Queiros A, Gonzalez-Meijome JM, Fernandes P, et al. Technical note: a comparison of central and peripheral intraocular pressure using rebound tonometry. Ophthalmic Physiol Opt. 2007:27:506-511.

12. Kontiola A, Puska P. Measuring intraocular pressure with the Pulsair 3000 and Rebound tonometers in elderly patients without an anesthetic. Graefes Arch Clin Exp Ophthalmol. 2004;242:3-7.

13. Davies LN, Bartlett H, Mallen EA, et al. Clinical evaluation of rebound tonometer. Acta Ophthalmol Scand. 2006;84:206-209.

14. Kontiola AI. A new induction-based impact method for measuring intraocular pressure. Acta Ophthalmol Scand. 2000;78:142-145.

15. Kontiola AI, Goldblum D, Mittag T, et al. The induction/impact tonometer: a new instrument to measure intraocular pressure in the rat. Exp Eye Res. 2001;73:781-785.

16. Fernandes P, Diaz-Rey JA, Queiros A, et al. Comparison of the ICare $(\mathrm{R})$ rebound tonometer with the Goldmann tonometer in a normal population. Ophthalmic Physiol Opt. 2005;25: 436-440.

17. Garcia-Resua C, Gonzalez-Meijome JM, Gilino J, et al. Accuracy of the new ICare rebound tonometer vs. other portable tonometers in healthy eyes. Optom Vis Sci. 2006;83:102-107.

18. Martinez-de-la-Casa JM, Garcia-Feijoo J, Castillo A, et al. Reproducibility and clinical evaluation of rebound tonometry. Invest Ophthalmol Vis Sci. 2005;46:4578-4580.

19. Queiros A, Gonzalez-Meijome JM, Fernandes P, et al. Technical note: accuracy and repeatability of a new portable ultrasound pachymeter. Ophthalmic Physiol Opt. 2007;27:190-193.

20. Parafita M, Yebra-Pimentel E, Giraldez MJ, et al. Further information on the knowledge of topographical corneal thickness. Int Contact Lens Clin. 1999;26:128-137.

21. Parafita MA, Gonzalez-Meijome JM, Diaz-Rey JA, et al. Corneal thickness mapping by topographical ultrasonic pachymetry. Int Contact Lens Clin. 2000;27:12-21.

22. Gonzalez-Meijome JM, Gonzalez-Perez J, Cervino A, et al. Changes in corneal structure with continuous wear of high-Dk soft contact lenses: a pilot study. Optom Vis Sci. 2003;80:440-446.

23. Gonzalez-Meijome JM, Cervino A, Yebra-Pimentel E, et al. Central and peripheral corneal thickness measurement with Orbscan II and topographical ultrasound pachymetry. J Cataract Refract Surg. 2003;29:125-132.

24. Liu J, Roberts CJ. Influence of corneal biomechanical properties on intraocular pressure measurement: quantitative analysis. J Cataract Refract Surg. 2005;31:146-155.

25. Herndon LW. Measuring intraocular pressure-adjustments for corneal thickness and new technologies. Curr Opin Ophthalmol. 2006; 17:115-119. 